\title{
Bilateral idiopathic calf muscle hypertrophy: An exceptional cause of unsightly leg
}

\section{curvature}

\section{L'hypertrophie musculaire idiopathique des mollets : une cause exceptionnelle d'altération du galbe de la jambe}

\author{
C. Herlin ${ }^{a, *, b}$ B. Chaput ${ }^{c}$, F. Rivier ${ }^{\text {d }}$, J.C. Doucet ${ }^{a}$, M. Bigorre ${ }^{a}$, \\ G. Captier ${ }^{\mathrm{a}, \mathrm{e}}$
}

${ }^{a}$ Department of Plastic Pediatric and Craniofacial Surgery - Lapeyronie University Hospital of Montpellier, 325, avenue du Doyen-Gaston-Giraud, 34295 Montpellier cedex 5, France

${ }^{\mathrm{b}}$ Department of Plastic and Reconstructive Surgery, Wound Healing and Burns Units-Lapeyronie University Hospital of Montpellier, Montpellier, France

'Department of Plastic, Reconstructive and Aesthetic Surgery, Rangueil University Hospital of Toulouse, Montpellier, France

${ }^{\mathrm{d}}$ Department of Pediatric Neurology, Faculty of Medecine, University of Montpellier, Montpellier, France

${ }^{\text {e }}$ Laboratory of Anatomy, Faculty of Medecine, University of Montpellier, Montpellier, France

\section{KEYWORDS \\ Calf; \\ Hypertrophy; \\ Muscle; \\ Gastrocnemius; \\ Resection}

\section{MOTS CLÉS}

Mollets ;
Summary The authors present the management of a young female patient who presented with longstanding bilateral calf muscle hypertrophy, with no known cause. Taking into account the patient's wishes and the fact that the hypertrophy was mainly located in the posteromedial compartment, we chose to carry out a subtotal bilateral resection of medial gastrocnemius muscles. This procedure was performed with an harmonic scalpel, permitting a excellent cosmetic result while avoiding complications or functional impairment. After a reviewing of the commonly used techniques, the authors discuss the chosen surgical approach taking into account its clinical particularity. (C) 2014 Elsevier Masson SAS. All rights reserved.

Résumé Nous présentons ici la prise en charge d'une jeune patiente présentant une hypertrophie musculaire des mollets sans cause retrouvée. Considérant les souhaits de la patiente, ses antécédents et le siège de l'hypertrophie, nous avons choisi de réaliser une résection sub-totale

\footnotetext{
* Corresponding author.

E-mail address: drchristianherlin@gmail.com (C. Herlin).
} 
Hypertrophie ;

Muscle ;

Gastrocnémien ;

Résection bilatérale du muscle gastrocnémien médial. Cette procédure a été réalisée à l'aide d'un bistouri harmonique, permettant un excellent résultat cosmétique tout en diminuant les risques de complications ou de déficience fonctionnelle. Après avoir revu les techniques couramment utilisées dans ce cadre pathologique, les auteurs discutent de l'approche chirurgicale choisie en tenant compte de sa particularité clinique.

\section{Introduction}

Calf hypertrophy is a common reason of consultation for female patients. Usually, the patients would like the circumference of the calves to be reduced due to an increase in the subcutaneous adipose tissue, and a lack of curvature between the knees and the ankles [1]. Liposuction enables the circumference to be reduced and can re-establish the calf curvature that is so important in the modern female silhouette. However, muscular hypertrophy in the calves is rare [2-6]. Here, we report the unusual management of a young female patient who presented with longstanding bilateral calf hypertrophy, of unknown cause, which result in major functional and aesthetic impairment.

\section{Case report}

A 23-year-old woman presented with a request for a reduction in the volume of her calves. She had a history of disabling calf pain on effort, and neuromuscular disease had been suspected related to the muscular hypertrophy. At the age of 17 , due to the increased of volume and pain during exercise, another surgical team performed an aponevrotomy on both legs. The intervention has unfortunately not led to a pain reduction. Anatomicopathological, immunohistochemical (dystrophin, $\alpha \beta$ dystroglycans, $\alpha \beta \gamma \delta$ sarcoglycans, dysferlin, and calveolin 3) and biochemical (dystrophin and calpain) tests were carried out on several biopsies without providing a diagnosis.

From a functional point of view, the patient became during childhood gradually unsuitable for sports. During long walk or exercise, the patient described significant pain like cramping or burns. The strength of the triceps has not been evaluated in a standardized manner but seemed good on clinical examination.

Aesthetically, the main impairment was centered around the proximal and medial part of the leg (Fig. 1). The maximal circumference of the right calf was $39.5 \mathrm{~cm}$ and $38 \mathrm{~cm}$ in left side. A preoperative MRI showed major hypertrophy of triceps surae, with the medial gastrocnemius predominating; there was no other obvious anomaly in the other muscles or the intermuscular fasciae (Fig. 2).

As the hypertrophy was mainly located in the posteromedial compartment, we chose, in agreement with the neurological team, to carry out a total resection of both medial gastrocnemius muscles. The operation was carried out under general anaesthesia and plexic block (popliteal sciatic and femoral), and we followed the initial medial approach which had been taken for the aponevrectomy. This incision allowed us to control the dissection, preserving all the adjacent neurovascular structures (the medial and lateral sural nerves, and the motor nerve supplying the lateral gastrocnemius and calf muscles). We preserved a $3 \mathrm{~cm}$ transversal band of muscle proximally in order to avoid hollowness in the lower part of the popliteal fossa.

A harmonic scalpel (Harmonic Focus ${ }^{\mathrm{TM}}$, Ethicon Endosurgery, Cincinnati) was used in order to minimize the haematomas and seromas previously described in this type of surgery [5].

On the right side, $530 \mathrm{~g}$ of muscle was removed; on the left, $470 \mathrm{~g}$. Dissection time was less than 1 hour on each side (Fig. 3). At the end of the operation, $3 \mathrm{~cm}$ of skin was removed. Drainage was maintained for 5 days, and prophylactic anticoagulation was given for $\mathbf{1 5}$ days. Biological and histological examination of the surgical specimen have failed to obtain additional information.

Postoperative recovery was straightforward, with a progressive return to normal mobility over two weeks. There was no haematoma nor seroma, and no loss of sensitivity or power on clinical examination. The functional and cosmetic result was considered to be excellent by the patient. Postoperatively, the calf circumference was $33.5 \mathrm{~cm}$ on the

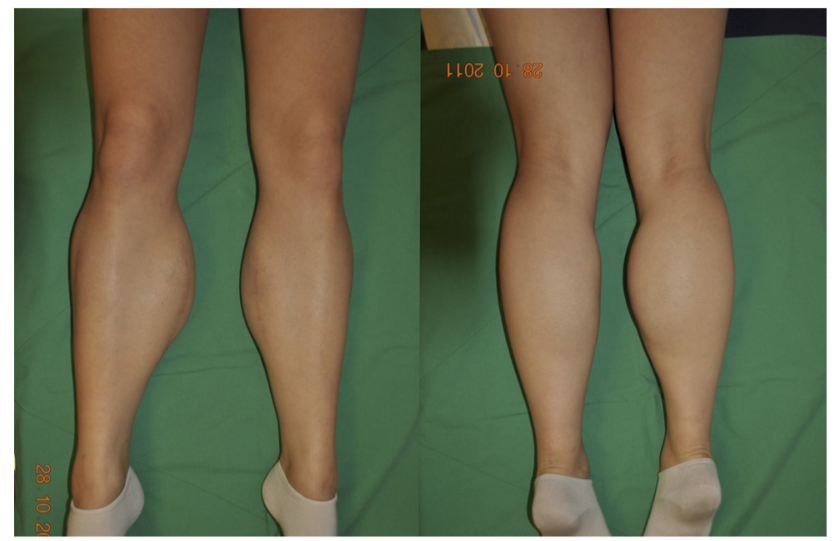

Figure 1 Preoperative appearance. Hypertrophy involves mainly the medial edge and the right side.

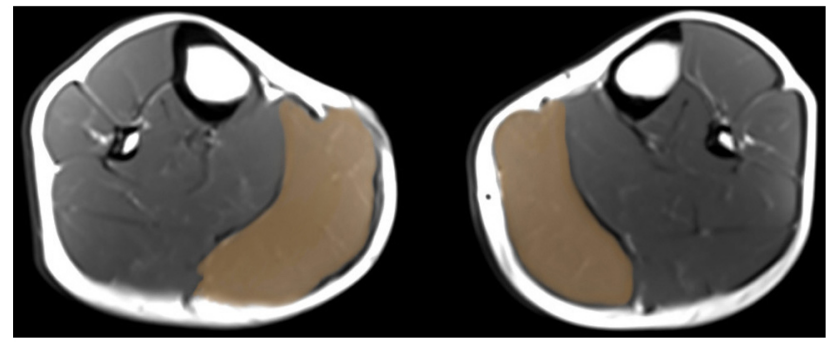

Figure 2 MRI axial slices. The muscular hypertrophy was mainly found in the posterior and medial compartments. 


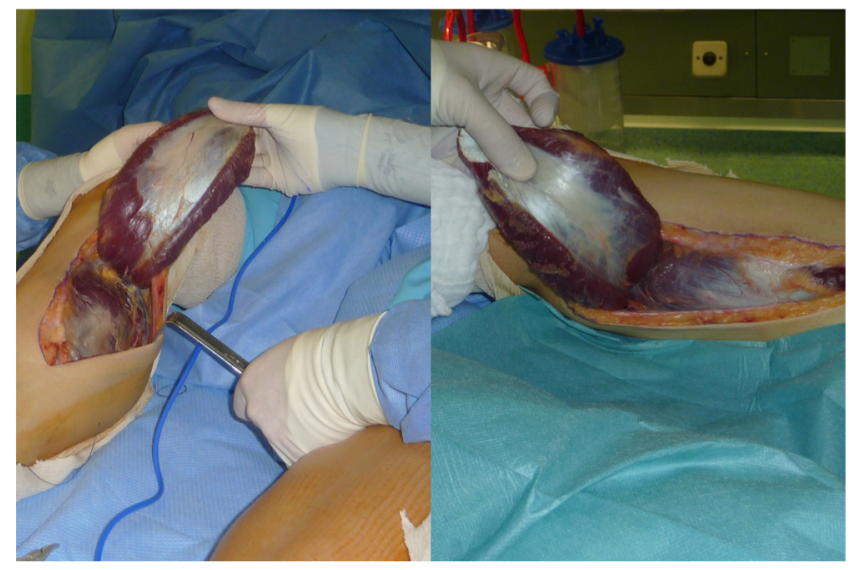

Figure 3 Peroperative view. The hypertrophied muscle had a normal appearance, and no anatomical variation was found during the dissection.

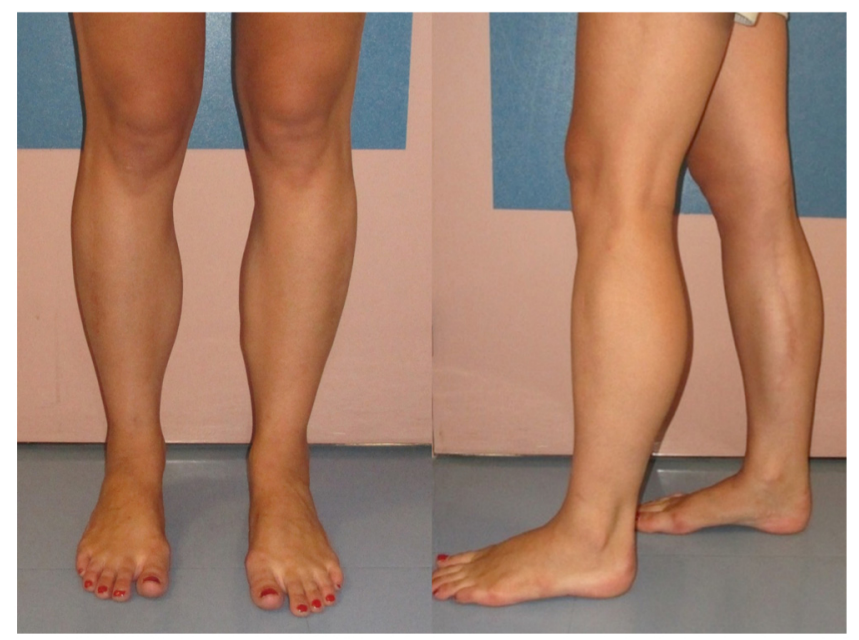

Figure 4 Aspect at three months postoperatively. Both legs had a more harmonious appearance.

right, and $33 \mathrm{~cm}$ on the left, this being an average decrease of $5.5 \mathrm{~cm}$ (Fig. 4).

\section{Discussion}

Calf hypertrophy is mostly due to fat hypertrophy. This anomaly is accessible to liposuction. which enables to improve calf and ankle contour [1].

Muscular hypertrophy of the calves is rare. This pathology can be due to chronic polyneuropathy, radiculopathy, motor neurone disease, muscular dystrophy, or poliomyelitis. It can be treated with neurectomy $[2,4,7]$, radiofrequency [8], injection of type A botulinum toxin [9], or muscle resection $[3,5,6]$. These treatments can cause little or no functional deficit $[3,5,7,10]$.

Selective neurectomy as well described by Fong et al. [2] is able to reduce the discrepancies between asymetric leg contours with a very discreet scar morbidity. This quite interesting technique allows a reduction of the three composant of the triceps surae muscle with an average reduction of $2.7 \mathrm{~cm}$.

Radiofrequency is also interesting for hypertrophy involving the upper part of calf muscles. It allows atrophy of the muscle treated. Park et al. [8] describes a mean reduction of
$2.5 \mathrm{~cm}$ on nearly 500 procedures. The scar morbidity is also particularly interesting. The follow-up was unfortunately 17 months in this study and this technique requires a re-evaluation in the long term due to a higher risk of recurrence. The method also seems more difficult than in the selective neurectomy exposing lesions to the adjacent neurovascular structures.

The literature mainly describes non-pathological cases treated with resection, mostly in the Asian population $[3,5,6]$. The subtotal resection as described by Lee et al. [5] was a good alternative to our surgical approach choice. The classical medial incision was justified by the previous internal scarring and because hypertrophy was predominatly localized to the medial gastrocnemius muscle. This procedure enabled a very good control in the dissection, and skin resection with a satisfactory cosmetic result. The use of the Harmonic scalpel allowed a bloodless proximal transverse resection and avoid a hollow in the popliteal fossa.

\section{Conclusion}

Muscular hypertrophy of one or both calves is rare. Histopathological, biochemical and radiological (e.g., MRI) investigations should be carried out before deciding on treatment. 
If the hypertrophy is major and the subcutaneous tissue is normal, muscle resection seems a treatment of choice. Selective neurotomy and radiofrequency appear to be a good alternative with a minimal scarring. These two techniques are particularly interesting when hypertrophy concerns the whole triceps sural or in case of asymmetry due to neurologic sequelae.

Volumetric radiological analyses help to determine if partial or total resection of the gastrocnemius is required. Minimally invasive or endoscopic route seems interesting but an internal approach allows perfect control in the dissection, and reduces the risk of complications. It must be, however, carried out with the patient's agreement, and used only when complete huge muscle resection is needed. The outcome in terms of scarring must, of course, be balanced against that of other methods and liposuction should automatically be considered.

\section{Ethics}

This study follows the principles of the World Medical Association Declaration of Helsinki.

\section{Disclosure of interest}

The authors declare that they have no conflicts of interest concerning this article.

\section{References}

[1] Mladick RA. Advances in liposuction contouring of calves and ankles. Plast Reconstr Surg 1999;104(3):823-31.

[2] Fong TH, Wong CH, Lin JY, Liao CK, Ho LY, Tsai FC. Correction of asymmetric calf hypertrophy with differential selective neurectomy. Aesthetic Plast Surg 2010;34(3):335-9.

[3] Kim IG, Hwang SH, Lew JM, Lee HY. Endoscope-assisted calf reduction in orientals. Plast Reconstr Surg 2000;106(3):713-8.

[4] Kim SC, Kang MH, Ock JJ. Calf-contouring surgery of gastrocnemius hypertrophy: selective neurectomy of the sural nerve. Aesthetic Plast Surg 2008;32(6):889-93.

[5] Lee JT, Wang CH, Cheng LF, Lin CM, Huang CC, Chien SH. Subtotal resection of gastrocnemius muscles for hypertrophic muscular calves in Asians. Plast Reconstr Surg 2006;118(6):1472-83.

[6] Lemperle G, Exner K. The resection of gastrocnemius muscles in aesthetically disturbing calf hypertrophy. Plast Reconstr Surg 1998;102(6):2230-6.

[7] Hwang K, Kim YJ, Chung IH, Won HS, Tanaka S, Lee SI. Innervation of calf muscles in relation to calf reduction. Ann Plast Surg 2003;50(5):517-22.

[8] Park YJ, Jo YW, Bang SI, Kim HJ, Lim SY, Mun GH, et al. Radiofrequency volume reduction of gastrocnemius muscle hypertrophy for cosmetic purposes. Aesthetic Plast Surg 2007;31(1):53-61.

[9] Lee HJ, Lee DW, Park YH, Cha MK, Kim HS, Ha SJ. Botulinum toxin a for aesthetic contouring of enlarged medial gastrocnemius muscle. Dermatol Surg 2004;30(6):867-71.

[10] Greenberg B, LaRossa D, Lotke PA, Murphy JB, Noone RB. Salvage of jeopardized total-knee prosthesis: the role of the gastrocnemius muscle flap. Plast Reconstr Surg 1989;83(1):85-9. 